\title{
REDES DE PEQUENAS EMPRESAS COMO ESTRATÉGIA PARA 0 DESENVOLVIMENTO DA AGRICULTURA ORGÂNICA
}

\author{
SMALL BUSINESS NETWORKS AS A STRATEGY FOR THE \\ DEVELOPMENT OF ORGANIC AGRICULTURE
}

\author{
Jaqueline de Fátima Cardoso ${ }^{1}$ \\ Nelson Casarotto Filho ${ }^{2}$ \\ Artur Santa Catarina ${ }^{3}$
}

\begin{abstract}
Resumo
Uma estratégia possível a ser adotada por produtores orgânicos é participar de uma rede de empresas. $\mathrm{O}$ objetivo deste estudo consiste em descrever uma rede de empresas voltada à produção orgânica, evidenciando sua estrutura organizacional e configuração, a caracterização dos atores envolvidos na rede, e as relações entre esses atores. A abordagem utilizada é a qualitativa e o estudo de caso foi realizado em uma rede de pequenas empresas no contexto da agricultura orgânica, localizada na Região Sul do Brasil. Este estudo contribui para compreender a estrutura organizacional, a configuração, a caracterização dos atores, bem como as relações entre esses atores no âmbito de redes de agricultores no contexto da produção orgânica, de modo a colaborar com o seu desenvolvimento, bem como com o desenvolvimento da região na qual a rede atua. Os atores que compõem as redes podem ser caracterizados como gestão, produtores, consumidores, comerciantes, instituições públicas, organizações parceiras e de assessoria. Com relação à centralidade dos atores na rede pesquisada, o protagonismo fica com uma organização não governamental e os produtores. Os atores que apresentam apenas uma conexão são três, isso mostra que grande parte dos atores se relacionam mutuamente. A participação de instituições públicas na rede é pequena, e atores que fornecem serviços de assessoria são elementos com influência relevante.
\end{abstract}

Palavras-chave: Agricultura orgânica; Redes de pequenas empresas; Redes de cooperação; Gestão de redes.

\footnotetext{
Abstract

One possible strategy to be adopted by organic producers is to participate in a business network. The objective of this study is to describe a business network focused on organic production, showing its organizational structure and configuration, the characterization of the players involved in the

${ }^{1}$ Doutora em Engenharia de Produção pela UFSC. Docente do Instituto Federal de Educação, Ciência e Tecnologia de Santa Catarina, Florianópolis - SC, Brasil. E-mail: jaquelinecardoso@yahoo.com.br

${ }^{2}$ Doutor em Engenharia de Produção pela UFSC. Professor da Universidade Federal de Santa Catarina, Florianópolis - SC, Brasil. E-mail: nelson.casarotto@ufsc.br

${ }^{3}$ Doutor em Engenharia de Produção pela UFSC. Professor da Universidade Federal de Santa Catarina, Florianópolis - SC, Brasil. E-mail: artur.catarina@ufsc.br
} 
network, and the relationships between these players. The approach used is qualitative and the case study was carried out in a small business network in the context of organic agriculture, located in the Southern Region of Brazil. This study contributes to understanding the organizational structure, configuration and characterization of the actors, as well as the relationships among these actors within the networks of farmers in the context of organic production, in order to collaborate with their development, as well as with the development of the region in which the network operates. The actors that make up the networks can be characterized as management, producers, consumers, traders, public institutions, partner organizations and advisory. With regard to the centrality of the actors in the researched network, the protagonism is with a non-governmental organization and the producers. The actors with only one connection are three, this shows that most actors relate to each other. The participation of public institutions in the network is small and actors who provide advisory services are elements with relevant influence.

Keywords: Organic farming; Small business networks; Cooperation networks; Network management.

\section{Introdução}

O produtor orgânico lida com diferentes desafios. De um lado, o mercado exige variedade e qualidade dos produtos; de outro, as exigências para produzir dentro das normas exigidas a fim de obter certificação. Somando a isso, o produtor necessita comercializar sua produção, seja por meio de venda direta ao consumidor final ou por intermédio de revendedores.

O cenário atual demonstra que as pessoas estão propensas a participar de diferentes formas associativas. As redes sociais são exemplos disso. Na sociedade em rede, o aumento das conexões entre as pessoas possibilitou o surgimento do que se denomina economia compartilhada (CHASE, 2015). Para Kennedy (2015), a economia compartilhada é uma forma de intensificação de relações sociais. Enquanto a economia capitalista se sustenta numa lógica individual, privada e competitiva, a economia colaborativa se fundamenta numa perspectiva de relações grupais, cooperativas e compartilhadas (RAMALHO e SILVA, 2016). Nesse contexto, surge o consumo colaborativo que consiste em um modo de acomodar necessidades e desejos de uma forma mais sustentável e atraente, com pouco ônus para o indivíduo (BOTSMAN e ROGERS, 2010).

Tal pensamento fomenta pequenas empresas a buscarem formas associativas com o intuito de melhorar o desempenho de seus negócios. Na mesma direção, consumidores agrupam-se na busca do consumo colaborativo de modo a incrementar a experiência de consumir. Nesse sentido, consumir produtos orgânicos diretamente de pequenos produtores possibilita conhecer a origem do alimento, o caminho que o mesmo percorreu até ser consumido, além de fomentar o desenvolvimento regional. O consumo de produtos orgânicos melhora a qualidade de vida dos produtores porque não utiliza insumos que prejudicam a saúde, incrementa a remuneração dos mesmos, pois produzir de forma orgânica agrega valor ao produto, bem como contribui para a preservação do meio ambiente (CARDOSO, 2016).

Pequenos produtores e agricultura orgânica, dois temas interligados, mas que necessitam de uma terceira temática para assegurar a competitividade, que é a temática das redes de empresas. Parte da produção da agricultura orgânica vem de pequenos agricultores. Uma estratégia possível de ser adotada por esses produtores é participar de uma rede de empresas, pois estar em rede pode ser uma alternativa para a sobrevivência de pequenos negócios. Na visão de Casarotto Filho (2010), pequenas empresas têm dificuldades ou maiores limitações para competir isoladamente. Devido à limitação de recursos, o crescimento dessas organizações é lento, pois o crescimento rápido exige grandes investimentos.

Para Casarotto Filho e Pires (2001), redes de empresas constituem um conjunto de empresas interligadas por relacionamentos formais ou negociais, podendo ou não ser circunscrito e uma região. A formação de uma rede de cooperação empresarial, na visão de Balestrin e Verschoore (2008), fundamenta-se em determinados elementos, a saber: objetivos comuns, ganhos competitivos, interação entre os integrantes e gestão.

Tendo em vista o crescimento da demanda por alimentos orgânicos (ARBOS et al., 2010; MAXEY, 2006; TRAUGER, 2009; LOUDEN e MACRAE, 2010; DEMIRYUREK, 2010; ZANOLI, GAMBELLI e VAIRO, 2012; RETAMALES, 2011), o desenvolvimento de redes de pequenas empresas nesse contexto torna-se relevante para promover e fortalecer a produção, abrangendo as 
três dimensões da sustentabilidade apontadas por Zahm et al. (2008) - sócio-territorial, econômica e agroecológica.

Frente ao exposto, este trabalho tem como objetivo descrever uma rede de empresas voltada à produção orgânica, evidenciando sua estrutura organizacional e configuração, a caracterização dos atores envolvidos na rede e as relações entre esses atores. A contribuição deste estudo caminha no sentido de compreender a configuração e o funcionamento de redes de agricultores no contexto da produção orgânica, de modo a colaborar com o seu desenvolvimento, bem como com a região na qual realiza suas atividades.

A estrutura deste artigo contempla, além desta introdução, o referencial teórico voltado para agricultura orgânica e redes de empresas, em seguida são apresentados os procedimentos metodológicos, resultados e discussões, finalizando com as conclusões.

\section{Referencial teórico}

\section{Agricultura orgânica}

A agricultura orgânica baseia-se na melhoria da fertilidade do solo por um processo biológico natural que inclui o uso da matéria orgânica, o que é essencial à saúde das plantas. Esse tipo de agricultura é totalmente contra a utilização de adubos químicos solúveis e de organismos geneticamente modificados. A agricultura orgânica apresenta um conjunto de normas determinadas e aceitas internacionalmente e nacionalmente que são definidas para produção e comercialização da produção. Atualmente, o nome "agricultura orgânica" é utilizado em países de origem anglo-saxã, germânica e latina. Pode ser considerado como sinônimo de agricultura biológica e engloba as práticas agrícolas da agricultura biodinâmica e natural (DAROLT, 2010).

Os produtos originários da agricultura orgânica são denominados, no Brasil, produtos orgânicos. A partir de 2010, todo produto orgânico brasileiro, exceto aqueles vendidos diretamente pelos agricultores familiares em feiras, levam o selo do Sistema Brasileiro de Avaliação da Conformidade Orgânica (SisOrg). Para a denominação "orgânico" ou "produto orgânico" no rótulo, o produto deve conter, no máximo, $5 \%$ de ingredientes não orgânicos os quais devem ser discriminados (MINISTÉRIO DA AGRICULTURA, PECUÁRIA E ABASTECIMENTO, 2019a).

O conceito de sistema orgânico de produção, para Zoldan e Mior (2012), abrange os denominados ecológico, biodinâmico, natural, sustentável, regenerativo, biológico, agroecológico e permacultura.

$\mathrm{Na}$ Europa, o apoio do governo para a agricultura orgânica começou no final de $1980 \mathrm{com}$ base em um reconhecimento dos benefícios ambientais mais amplos da agricultura orgânica (STOLZE e LAMPKIN, 2009). No Brasil o apoio a esse tipo de agricultura iniciou-se mais tarde. Em outubro de 2013, foi lançado o plano nacional de agroecologia e produção orgânica, denominado Brasil Ecológico, cuja principal missão é articular as políticas e as ações de incentivo ao cultivo de alimentos orgânicos e com base agroecológica (PORTAL BRASIL, 2014). O referido plano destinou $80 \%$ do investimento inicial para crédito agrícola por meio do Programa Nacional de Fortalecimento da Agricultura Familiar (Pronaf) e do Plano Agrícola e Pecuário, e 20\% dos recursos financeiros foram destinados para ações específicas, como qualificação e promoção de assistência técnica e extensão rural, desenvolvimento e disponibilização de inovações tecnológicas e ampliação do acesso aos mercados institucionais, como o Programa de Aquisição de Alimentos (PAA) e o Programa Nacional de Alimentação Escolar (PNAE) (PORTAL BRASIL, 2014). Em um processo de continuidade e aperfeiçoamento do primeiro ciclo do Plano, foi lançado o Planapo 2016-2019, a partir das mesmas bases de ampla participação da sociedade civil. O Planapo 2016-2019 articula diversos Ministérios, unidades setoriais e entidades governamentais em torno de programas e ações indutoras da transição agroecológica e da produção orgânica e de base agroecológica. São 194 iniciativas, distribuídas em 30 metas e organizadas a partir de seis eixos estratégicos: Produção; Uso e Conservação de Recursos Naturais; Conhecimento; Comercialização e Consumo; Terra e Território e Sociobiodiversidade (BRASIL ECOLÓGICO, 2019).

No Brasil, a certificação dos produtos orgânicos pode ser realizada por meio de auditoria ou por certificação participativa. A certificação por auditoria é feita por empresas especializadas credenciadas pelo Ministério da Agricultura, Pecuária e Abastecimento (MAPA). A fiscalização das propriedades produtoras de orgânicos é feita por essas empresas, que assumem a responsabilidade pelo uso do selo brasileiro. Cabe ao MAPA fiscalizar o trabalho de tais certificadoras (MINISTÉRIO DA AGRICULTURA, PECUÁRIA E ABASTECIMENTO, 2019a). 
Por outro lado, a certificação participativa é efetuada através dos Sistemas Participativos de Garantia (SPG). São grupos formados por produtores, consumidores, técnicos e pesquisadores que se auto-certificam, ou seja, estabelecem procedimentos de verificação das normas de produção orgânica daqueles produtores que compõem o SPG. Precisam ser credenciados no MAPA que fiscaliza seu trabalho. Os produtos dos SPG também recebem o selo brasileiro, pois atendem às exigências legais para a certificação (MINISTÉRIO DA AGRICULTURA, PECUÁRIA E ABASTECIMENTO, 2019a).

A certificação participativa é um incentivo para o produtor orgânico brasileiro, pois esse tipo de certificação é responsável por 57\% dos produtores certificados. Na Região Sul, dos 6407 certificados, 4254 (66\%) têm certificação participativa. Isso se deve ao trabalho da Associação Ecovida de Certificação Participativa, que é responsável pela certificação de aproximadamente 82\% das certificações participativas (MAPA, 2019b).

Em abril/2019, o Cadastro Nacional de Produtores Orgânicos (MAPA, 2019b) registrava 18516 produtores orgânicos, destes 3430 eram certificados pela rede Ecovida, ou seja, 18,5\% dos produtores cadastrados.

\section{Redes de empresas}

O tema aglomerações produtivas apresenta diferentes denominações nos trabalhos pesquisados, a saber: clusters (PORTER, 1998); sistemas locais de produção, arranjos e sistemas produtivos locais (CASSIOLATO e LASTRES, 2010); redes de cooperação, redes de empresas, consórcios de empresas (CASAROTTO FILHO e PIRES, 2001); aglomerações e sistemas produtivos e inovativos locais (CASSIOLATO e SZAPIRO, 2002); redes de negócios (ZACARELLI et al., 2008); redes de cooperação empresarial (BALESTRIN e VERSCHOORE, 2008) e redes interorganizacionais (ROTH et al., 2012). Em linhas gerais, esses termos são utilizados para definir um conjunto de organizações que atuam em determinado setor, podem estar circunscritos a uma região ou não, são interdependentes e têm relacionamentos com diferentes graus de profundidade. Todavia, muitas vezes é difícil delimitar fronteiras claras entre as diferentes nomenclaturas. Para efeito deste estudo, será utilizado o termo redes de empresas.

Um estudo sobre essas diferentes definições foi feito por Gonçalves, Leite e Silva (2012). Para os autores, a literatura utiliza diversas nomenclaturas e classificações, seja em função da forma como o arranjo é gerido; seja no modo como está organizado; na conformidade com que os membros exercem suas atividades; na forma como ocorre o fluxo de recursos e informações; seja no grau de articulação e interação; na forma de organização da produção e nas estratégias adotadas.

As redes de cooperação empresarial podem ser definidas como organizações compostas por um grupo de empresas formalmente relacionadas, com objetivos comuns, com prazo de existência ilimitado, com escopo múltiplo de atuação e com estrutura formal própria. Nelas, cada membro mantém sua individualidade legal, participa diretamente das decisões e dividem simetricamente com os demais os benefícios e ganhos alcançados pelos esforços coletivos (BALESTRIN e VERSCHOORE, 2008).

Casarotto Filho e Pires (2001) observam que redes de pequenas empresas promovem o desenvolvimento regional. Os autores apresentam dois tipos de classificação para essas redes. A rede topdown ou vertical que se caracteriza pelo fato de que empresas de menor porte fornecem direta e indiretamente sua produção a uma empresa-mãe. Nesse caso, o fornecedor é altamente dependente da empresa-mãe e tem pouca ou nenhuma flexibilidade ou poder nos destinos da rede. Por outro lado, a rede horizontal ou flexível é formada por pequenas e médias empresas que se reúnem a partir da formação de uma organização com objetivos comuns. O conjunto das atividades desse consórcio e a sua forma de funcionamento fazem com que um conjunto de pequenas empresas atue como uma grande empresa. As redes de empresas pesquisadas neste estudo são horizontais.

Dentre as redes de empresas estão aquelas voltadas à agricultura, sendo que, nesse tipo de configuração organizacional, a produção orgânica vem ganhando incremento (ARBOS, 2010; MAXEY, 2006; TRAUGER, 2009; LOUDEN e MACRAE, 2010; RETAMALES, 2011; LOBLEY et al., 2009).

\section{Procedimentos metodológicos}


Este trabalho consiste em um estudo de caso, haja vista que as questões desta pesquisa são voltadas para "o que" e "como". O método do estudo de caso é uma investigação empírica que permite aos pesquisadores explorarem fenômenos contemporâneos em profundidade e em seus contextos de vida real, como, entre outros exemplos, os processos organizacionais. Especialmente quando os limites entre o fenômeno e o contexto não são claramente evidentes. Os estudos de casos são generalizáveis às proposições teóricas, pois sua meta é expandir e generalizar teorias (YIN, 2010).

Para Cauchick Miguel e Sousa (2012), a quantidade de casos a serem estudados deve ser definida na fase de planejamento do estudo e para isso apontam diferentes estratégias de seleção dos casos a serem adotadas. Frente ao exposto, o estudo em questão elegeu um caso denominados pelos autores de "revelador", pois representa uma das maiores redes de agricultura do Brasil e a maior da região sul.

A rede de empresas estudada trabalha exclusivamente com a produção orgânica, é horizontal e denomina-se rede Ecovida, mais especificamente foi estudado o Núcleo Litoral Catarinense. O estudo apresenta informações gerais sobre a rede, bem como aprofunda a análise de uma parte da mesma, ou seja, um de seus núcleos.

Os atores foram classificados de acordo com a atividade desenvolvida na rede e posteriormente selecionados para coleta de dados, tendo em vista obter a participação dos diferentes tipos de atores na pesquisa.

Na Ecovida, realizou-se 14 entrevistas semiestruturadas com diferentes atores do Núcleo Litoral Catarinense (NLC). Para levantar a caracterização dos produtores e dos produtos elaborados pelos mesmos, foi efetuada uma pesquisa tipo survey com utilização de questionários. Os questionários foram distribuídos a 96 produtores certificados do NLC, destes 43 foram respondidos.

As entrevistas foram gravadas e transcritas. Foi realizada análise de conteúdo das entrevistas e de documentos. As categorias de análise foram: estrutura organizacional e configuração das redes, caracterização dos atores envolvidos nas redes, e relações entre esses atores.

Para demonstrar a configuração e as relações entre atores da rede, foi utilizado o NodeXL para Microsoft ${ }^{\circledR}$ Excel ${ }^{\circledR}$. Tal ferramenta também foi aplicada no estudo sobre análise de redes de empresas elaborado por De Rolt, Dias e Penha (2017).

\section{Resultados}

\section{Estrutura organizacional e configuração da rede Ecovida}

A Ecovida começou a ganhar forma em 1989 com o surgimento da Feira Ecológica da Colméia em Porto Alegre/RS. Em 1998, a partir da necessidade de congregar forças e dar maior consistência política ao movimento agroecológico da agricultura familiar do Sul do Brasil, foi criada a Rede Ecovida de Agroecologia. Ela emerge como resultado de processos históricos realizados por organizações não governamentais na construção de uma alternativa ao modelo de agricultura em curso caracterizado pela chamada Revolução Verde. É formada por pessoas e organizações que têm como objetivo organizar, fortalecer e consolidar a agricultura familiar ecológica. São agricultores, técnicos, consumidores e comerciantes unidos em associações, cooperativas, ONGs e grupos informais que constituem Núcleos Regionais e, juntos, formam a Rede Ecovida de Agroecologia.

Poucos anos após a criação da Rede Ecovida, foi constituída a Associação Ecovida de Certificação Participativa, especificamente voltada para a certificação e para a disponibilização de selo de produtor orgânico. No entanto, em face da não exigência do selo para as dinâmicas de comercialização locais/regionais e da resistência de muitos membros da Rede Ecovida ao uso do selo, a Associação Ecovida, apesar de constituída, permaneceu vários anos sem desempenhar as atividades para as quais foi criada. Apenas em 2010, com a previsão de encerramento do prazo para oficializar questões relacionadas à certificação, a Associação foi retomada e constituída como OPAC (Organismo Participativo de Avaliação da Conformidade), que é condição para compor o Sistema Brasileiro de Avaliação da Conformidade Orgânica (ROVER, 2011).

Tanto a Rede Ecovida quanto a Associação Ecovida de Certificação Participativa são formadas por grupos e por núcleos regionais que buscam promover a troca de informações, credibilidade e produtos. A Associação é considerada um braço operacional da Rede Ecovida, para permitir implementar o processo de certificação. Os núcleos (Figura 1) são formados por grupos em determinada região geográfica, facilitando a troca de informações e a certificação participativa. Sua importância, bem como a dinâmica descentralizada de tomada de decisões, evidencia a condição 
multidirecional e descentralizadora da Ecovida. A Associação tem sede localizada na cidade de Três Cachoeiras/RS, enquanto a rede não tem sede.

Ainda compõe a estrutura organizacional da Ecovida a coordenação geral estruturada de forma colegiada por membros representantes indicados nos estados e coordenadores de grupos de trabalho ativos. Vale lembrar que os núcleos são a principal unidade funcional da organização. Nestes, é onde acontecem as principais decisões e encaminhamentos organizativos da Ecovida. A estrutura da rede é horizontal e descentralizada. Para ocorrer o ingresso de novos aderentes, tanto na rede quanto na associação, é necessário obter o aceite do núcleo da região onde estão situados. $\mathrm{O}$ interessado em ingressar procura o grupo mais próximo de sua propriedade a fim de demonstrar sua intenção de participar da rede, geralmente um produtor do grupo o apadrinha e o ingressante passa a participar das reuniões do referido grupo.

Segundo o MAPA e o Centro de Estudos e Promoção da Agricultura de Grupo (Cepagro), a Ecovida é a rede de maior dimensão geográfica do Brasil e uma das maiores da América Latina. Os núcleos regionais estão espalhados pelos estados de Santa Catarina, Paraná e Rio Grande do Sul, abrangendo também algumas cidades do Estado de São Paulo.

Atualmente a rede conta com 27 núcleos regionais, abrangendo cerca de 352 municípios (Figura 1). Seu trabalho congrega, aproximadamente, 340 grupos de agricultores (abrangendo cerca de 4.500 famílias envolvidas) e 20 ONGs. Em toda a área de atuação da Ecovida, acontecem mais de 120 feiras livres ecológicas e ainda outras formas de comercialização. É formada por agricultores familiares, técnicos e consumidores reunidos em associações, cooperativas e grupos informais, juntamente com pequenas agroindústrias, comerciantes e pessoas comprometidas com o desenvolvimento da agroecologia. Nem todos os núcleos têm gestão realizada pelos próprios produtores, a maioria ainda depende de instituições apoiadoras para realizar a gestão.

Figura 1: Localização dos núcleos da Rede Ecovida

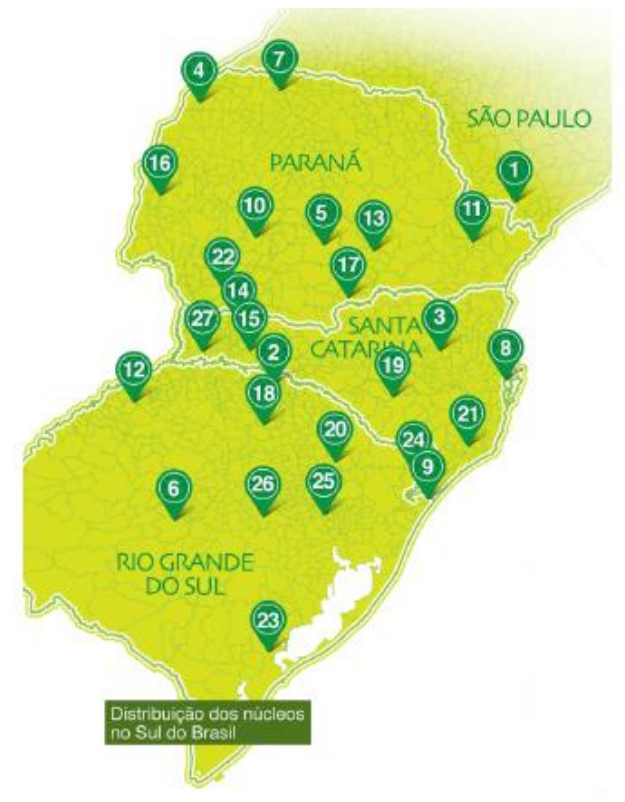

Fonte: Dados primários.

Conforme exposto, os núcleos são a principal unidade funcional da Rede Ecovida, os quais são compostos por grupos, que por sua vez reúnem produtores, agroindústrias, consumidores, instituições públicas e ONGs.

Um dos núcleos que apresenta gestão própria é o Núcleo Litoral Catarinense (NLC). Está entre os 10 núcleos do Estado de Santa Catarina, é formado por 14 grupos, e abrange cerca de 25 municípios (Figura 2). São 89 agricultores e 7 agroindústrias certificadas. Ao todo o núcleo conta com 110 contribuintes, pois existem unidades produtivas ainda não certificadas e outros aderentes que estão na rede, mas não desejam certificar.

Figura 2: Abrangência geográfica do NLC 


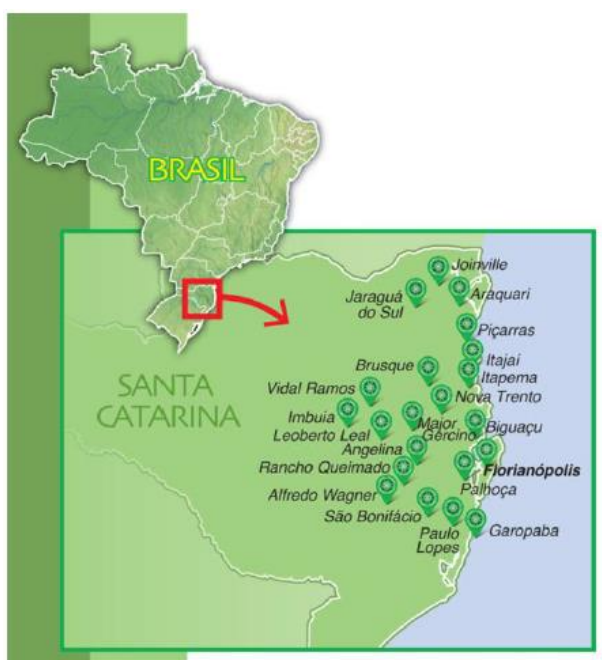

Fonte: Dados primários.

A estrutura organizacional do NLC é composta pelas funções de coordenação, tesouraria e secretariado, sendo que cada uma dessas funções é ocupada por uma pessoa. Ainda faz parte de estrutura uma comissão de ética formada por aderentes que realizam as visitas para a certificação. É sugerida a rotatividade nos cargos tanto do núcleo quanto dos grupos. Cada grupo tem um responsável por organizar as atividades do grupo e participar das reuniões bimestrais do núcleo.

$O$ relacionamento do NLC com toda a rede se dá por meio de reuniões e encontros. $O$ processo de certificação participativa exige frequentes contatos do núcleo com o organismo certificador (Associação Ecovida) que faz parte da rede.

\section{Caracterização dos atores da Ecovida}

A rede Ecovida tem uma classificação dos tipos de atores que participam da rede, conforme demonstra o Quadro 1.

Quadro 1: Caracterização dos atores da Rede Ecovida

\begin{tabular}{|l|l|}
\hline Tipo de atores & Caracterização \\
\hline $\begin{array}{l}\text { Produtores e grupos de } \\
\text { produtores }\end{array}$ & $\begin{array}{l}\text { Agricultores e criadores de animais. Associações e cooperativas de } \\
\text { produtores organizadas }\end{array}$ \\
\hline $\begin{array}{l}\text { Consumidores e suas } \\
\text { organizações }\end{array}$ & $\begin{array}{l}\text { Consumidores e grupos de consumidores que compram produtos } \\
\text { periodicamente }\end{array}$ \\
\hline $\begin{array}{l}\text { Processadores e } \\
\text { comerciantes de alimentos } \\
\text { orgânicos (microempresas) }\end{array}$ & $\begin{array}{l}\text { Agroindústrias. Empresas que comercializam produtos oriundos da rede } \\
\text { (pequenos comércios, feirantes, boxe 721 na Central de Abastecimento } \\
\text { do Estado de Santa Catarina (Ceasa), Laboratório de Comercialização } \\
\text { da Agricultura Familiar (Lacaf) }\end{array}$ \\
\hline $\begin{array}{l}\text { Organizações de assessoria } \\
\text { em agroecologia - ONGs, } \\
\text { instituições públicas }\end{array}$ & $\begin{array}{l}\text { Ministerio da Agricultura, Pecuária e Abastecimento, organismos não } \\
\text { governamentais de proteção ambiental e voltados para a agricultura, } \\
\text { Universidade Federal de Santa Catarina, prefeituras, Empresa de } \\
\text { Pesquisa Agropecuária e Extensão Rural de Santa Catarina (Epagri), } \\
\text { Centro de Estudos e Promoção da Agricultura de Grupo (Cepagro) }\end{array}$ \\
\hline $\begin{array}{l}\text { Pessoas e organizações } \\
\text { comprometidas com a } \\
\text { agroecologia }\end{array}$ & $\begin{array}{l}\text { Representantes do Conselho de Alimentação Escolar, Conselho de } \\
\text { Segurança Alimentar e Nutricional e Comissão Estadual de Produção } \\
\text { Orgânica, cooperações internacionais }\end{array}$ \\
\hline Gestão & $\begin{array}{l}\text { O Núcleo Litoral Catarinense da Ecovida é formado pelas funções de } \\
\text { coordenação, tesouraria e secretaria, sendo uma pessoa para cada } \\
\text { função. Não há funcionários contratados e as funções não são } \\
\text { remuneradas. Demais núcleos seguem a mesma estrutura. }\end{array}$ \\
\hline
\end{tabular}

Fonte: Elaborado pelos autores.

Tendo como ponto de partida os atores pesquisados, foi possível localizá-los a partir da ideia da cadeia produtiva (Figura 3). Observa-se que a rede tem integrantes que vão desde o produtor até o cliente final. Os atores de suporte são diversificados e relevantes para o desempenho da rede. 
Balizando as ações da rede, estão a gestão do núcleo e de toda a rede, uma ONG e o Ministério de Agricultura. O Centro de Estudos e Promoção da Agricultura de Grupo (Cepagro) é uma organização não governamental, cuja proposta é ampliar a atuação na agroecologia, agindo de forma participativa junto às comunidades rurais e urbanas necessitadas, a fim de realizar trabalho orientado para a organização popular. Até 2012, ocupou-se da coordenação da Rede Ecovida. Contudo, continua participando da rede, dando suporte técnico aos produtores. Os projetos junto aos apoiadores públicos e privados, nacionais ou internacionais, são elaborados considerando a Universidade Federal de Santa Catarina / Laboratório de Comercialização da Agricultura Familiar (Lacaf) como parceira nas ações e trabalhos desenvolvidos, envolvendo de maneira direta estudantes e professores.

A partir da análise dos questionários na pesquisa realizada com os produtores, observa-se em linhas gerais que a maioria dos agricultores é homem com idade entre 38 e 55 anos; tem formação entre ensino fundamental e médio; realizou curso de qualificação na área; suas propriedades são de até 20 hectares; conta com dois trabalhadores da família para desenvolver as atividades produtivas; não processa produtos na propriedade; participa de encontros entre produtores; participa da execução de ações da rede; participa das decisões relativas às atividades da rede; toma decisão sozinho e utiliza a coordenação da rede para dar suporte a sua tomada de decisão; leva em conta a demanda do cliente para produzir; comercializa sua produção via venda na propriedade, feiras e venda a instituições públicas; faz compras individualmente; faz entrega dos produtos com veículo próprio; utiliza métodos de produção além dos aconselhados pela rede; compartilha boas práticas de produção; realiza controle de qualidade na produção; realiza planejamento para até um ano; utiliza recursos financeiros próprios; apresenta aumento ou estabilidade nas vendas e concorda plenamente com as ações da coordenação da rede.

Figura 3: Atores pesquisados Ecovida NLC

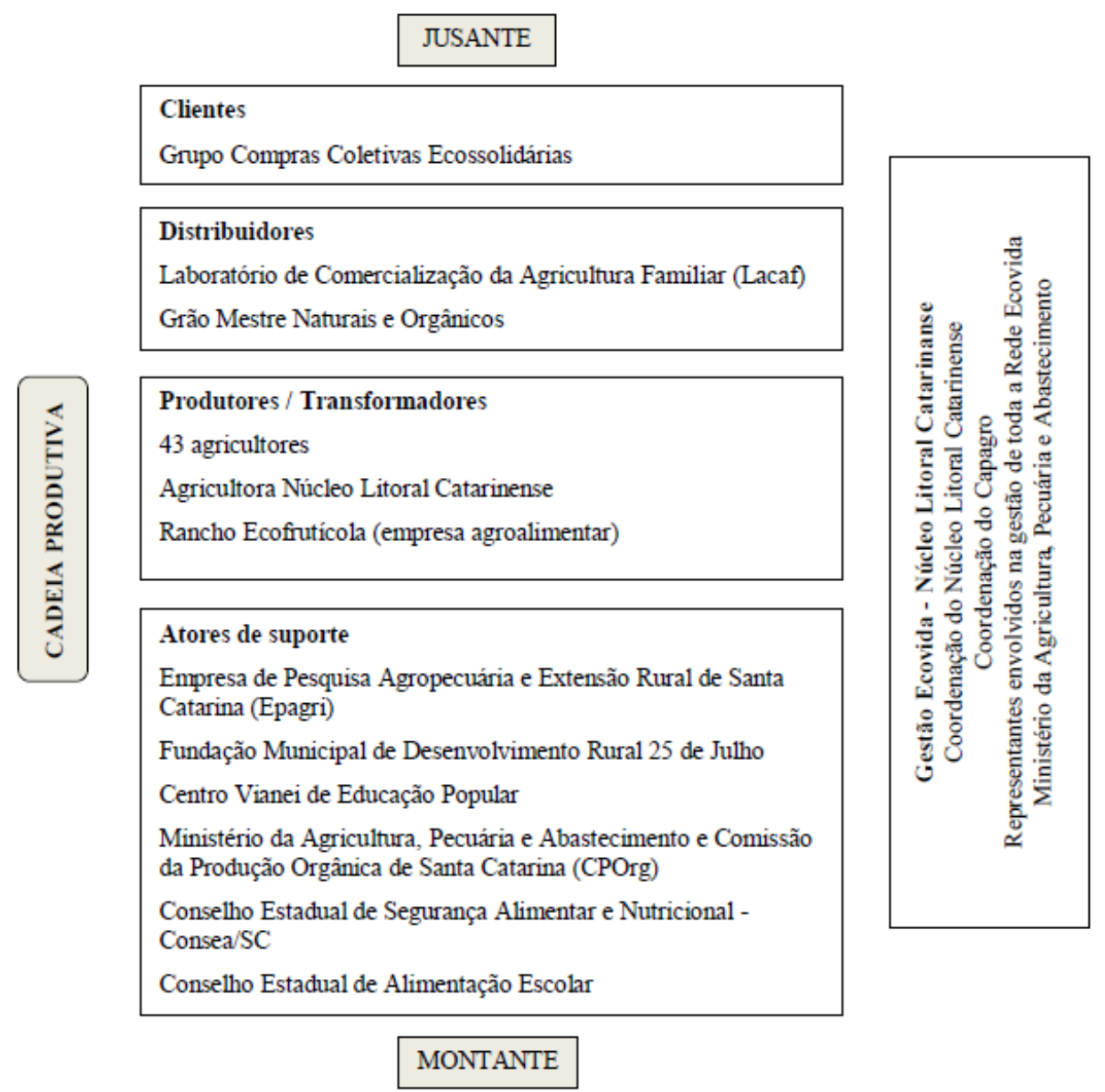

Fonte: Elaborados pelos autores.

Os produtos elaborados pelo NLC são: 
- Frutas: banana, morango, abacaxi, abacate, amora, ameixa, caqui, figo, fruta do conde, goiaba, graviola, jabuticaba, kiwi, laranja, mamão, uva, maracujá, pêssego, physalis, melancia, carambola, frutas cítricas, palmeira real, pitanga, bacupari, butiá, grumixama, cabeludinha e cambucá.

- Produtos hortícolas e grãos: verduras e legumes em geral, tomate, batatas, aipim, cará, milho, pimenta, tempero verde, feijão, flores de corte, cebola, milho, cará do ar, batata iacom, gengibre, pupunha, eucalipto, ervas medicinais e cana de açúcar.

- Produtos processados: leite, mel, ovos, queijo, derivados de aloe vera, farinha de mandioca, açúcar mascavo, molho pesto, infusão, temperos, açaí, biscoitos, suco de uva, vinho, geleias e conservas.

- Serviços: atividades educacionais.

\section{Relações entre atores da Ecovida NLC}

As relações entre atores da rede pesquisada podem ser observadas na Figura 4.

Figura 4: Relações entre atores Ecovida NLC

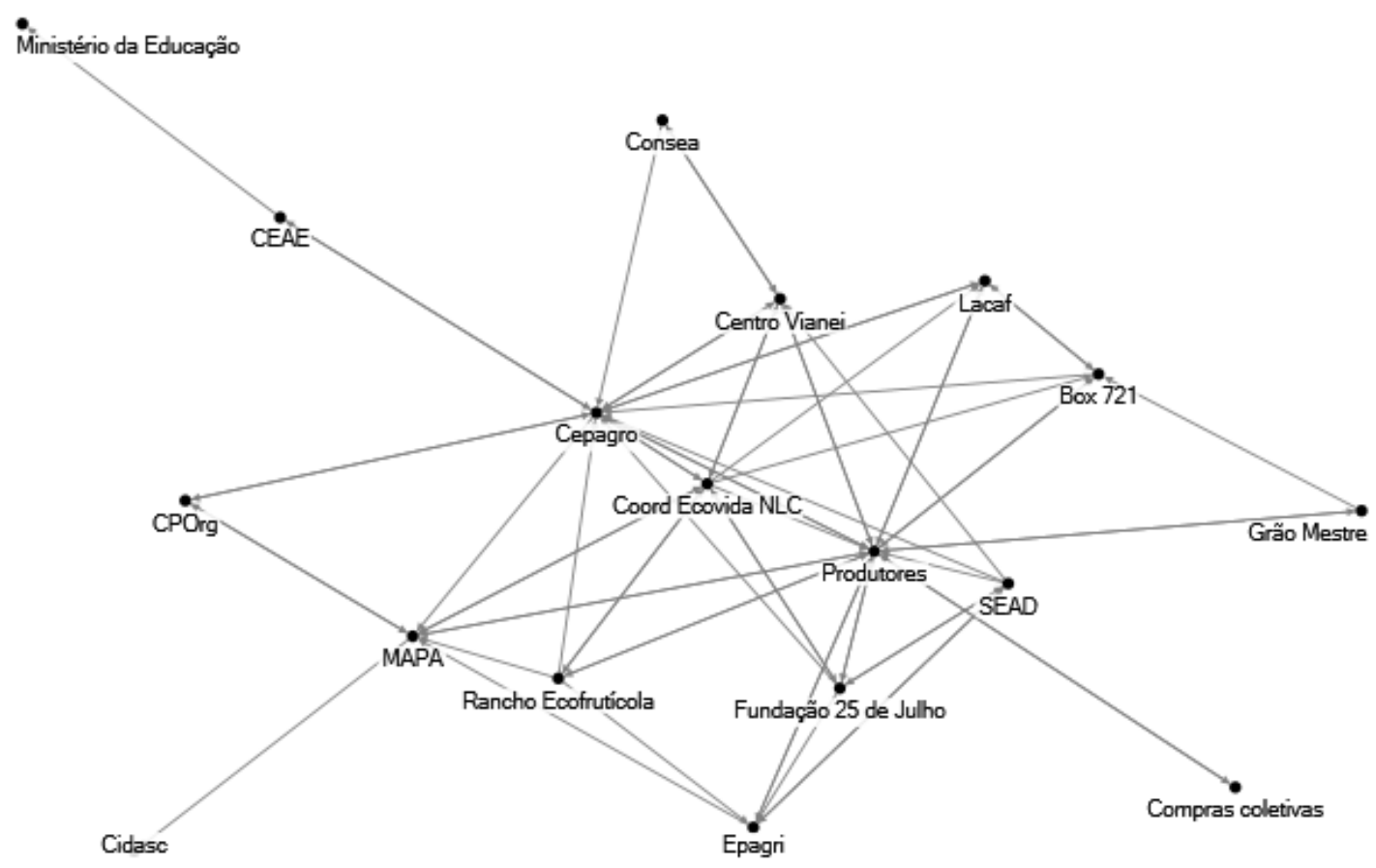

Fonte: Elaborados pelos autores.

A Figura 4 demonstra que o Cepagro e os produtores são os atores com mais conexões na rede, ambos com 12 ligações. A coordenação do NLC vem na sequência com 8 conexões e MAPA com 7. Centro Vianei, Fundação 25 de Julho, Empresa de Pesquisa Agropecuária e Extensão Rural de Santa Catarina (Epagri), Rancho Ecofrutícola, Box 721 e Secretaria Especial de Agricultura Familiar e do Desenvolvimento Agrário (SEAD) têm 5 conexões. Lacaf tem 4 conexões. Os demais atores apresentam 2 ( 4 atores) ou uma conexão ( 3 atores). As relações apresentadas apontam que o Cepagro é o grande articulador da rede, que, juntamente com os produtores, protagonizou as conexões. A coordenação tem certo grau de conexão, porém fica aquém dos dois atores principais. Dos 18 atores da rede, 7 são periféricos, pois têm apenas duas ou uma conexão. As organizações de assessoria são elementos com influência considerável, dado que caracterizam 8 atores. As instituições públicas caracterizam 5 atores, e as não governamentais compreendem 7 atores.

\section{Conclusão}


O objetivo deste estudo consistiu em descrever uma rede de empresas voltada à produção orgânica, evidenciando sua estrutura organizacional e configuração, a caracterização dos atores envolvidos na rede, e as relações entre esses atores. Os resultados apresentados responderam a esse propósito.

Estar em rede é uma estratégia adotada por diferentes tipos de empresas. Para as pequenas, essa estratégia é relevante e pode determinar sua sobrevivência no mercado. Isso pode ser observado em redes voltadas para a agricultura orgânica. O pequeno produtor isolado fica mais vulnerável. A rede lhe proporciona suporte para a resolução de problemas cotidianos no seu negócio, busca defender os interesses coletivos dos participantes, possibilita o compartilhamento de conhecimentos e, ainda, desenvolve no produtor certas características sociais decorrentes do processo participativo. Nessa direção, este estudo contribui para compreender a estrutura organizacional, a configuração, a caracterização dos atores, as relações entre esses atores no âmbito de redes de agricultores no contexto da produção orgânica, de modo a colaborar com o seu desenvolvimento, bem como com o desenvolvimento da região na qual a rede atua.

No Brasil, os dados sobre agricultura orgânica são de responsabilidade do MAPA, no entanto as informações ainda são escassas e restritas à quantidade de produtores e à área plantada. Nada consta sobre o mercado de orgânicos.

Com respeito à estrutura e configuração organizacional, na Ecovida a gestão da rede é um trabalho voluntário, não remunerado, exercido por poucas pessoas que dividem seu tempo entre a gestão e suas atividades como produtor. Em muitos casos, a administração dos grupos é realizada por organizações não governamentais. A gestão não recebe recursos financeiros públicos, cabendo aos integrantes da rede arcar totalmente com os gastos relativos à manutenção da mesma.

Os atores que compõem as redes podem ser caracterizados como gestão, produtores, consumidores, comerciantes, instituições públicas, organizações parceiras e de assessoria.

Com relação à centralidade dos atores na rede pesquisada, o protagonismo fica com uma ONG (Cepagro) e os produtores. Os atores que apresentam apenas uma conexão são três, isso mostra que grande parte dos atores se relacionam mutuamente.

A participação de instituições públicas na rede é pequena, pois não há incentivo financeiro específico para o produtor orgânico. As organizações não governamentais são determinantes para assessorar e incentivar as atividades da rede.

Atores que fornecem serviços de assessoria são elementos com influência relevante. Vale destacar que o apoio técnico oferecido aos produtores da rede é direcionado para grupos, ou seja, não são realizadas ações que privilegiem produtores individualmente. Isso fomenta a participação do produtor na rede, bem como o crescimento da mesma. A rede pesquisada é oriunda de movimentos sociais da sociedade civil. Nesse caso, cabe a reflexão sobre em que medida a criação artificial de estruturas em redes, pelo poder público, pode efetivamente instituir a cooperação, tendo em conta que essa é voluntária e individual.

As limitações deste estudo são relativas ao método do estudo de caso, no que se refere às restrições em utilizar seus resultados para outras realidades. Nessa direção, buscou-se a generalização analítica, escolhendo um caso revelador - representativo do campo estudado.

Finalmente, é possível indicar pesquisas futuras com o intuito de ampliar a quantidade de núcleos e grupamentos a serem pesquisados na Ecovida, bem como estudar outras redes de produção orgânica.

\section{Agradecimentos}

Este trabalho foi financiado com recursos da Coordenação de Aperfeiçoamento de Pessoal de Nível Superior (CAPES) - Ministério da Educação (Brasil). A pesquisa realizada na França contou com o apoio da Université de Poitiers - Institut d'Administration des Entreprises.

\section{Referências}

ARBOS, K. A.; FREITAS; R. J. S. STERTZ, S. C.; CARVALHO, L. A. Segurança alimentar de hortaliças orgânicas: aspectos sanitários e nutricionais. Ciência e Tecnologia de Alimentos 30(1), 215-220, 2010.

BALESTRIN, A.; VERSCHOORE, J. Redes de cooperação empresarial: estratégias de gestão na nova economia. Porto Alegre: Bookman, 2008. 
BOTSMAN, R.; ROGERS, R. What's mine is yours: the rise of collaborative consumption. New York: Harper Business, 2010.

BRASIL ECOLÓGICO. Disponível em: <http://www.mda.gov.br/planapo/> Acesso em: 01 maio 2019.

CARDOSO, J. F. Redes de pequenas empresas no contexto da agricultura orgânica: estratégias e instrumentos para a gestão. Tese de doutorado, Universidade Federal de Santa Catarina, 2016.

CASAROTTO FILHO, N. Elaboração de projetos empresariais: análise estratégica, estudo de viabilidade e plano de negócio. São Paulo: Atlas, 2010.

CASAROTTO FILHO, N.; PIRES, L. H. Redes de pequenas e médias empresas e desenvolvimento local: estratégias para a conquista da competitividade global com base na experiência italiana. São Paulo: Atlas, 2001.

CASSIOLATO, J.; LASTRES, M. H. Arranjos produtivos locais na indústria brasileira. Disponível em:

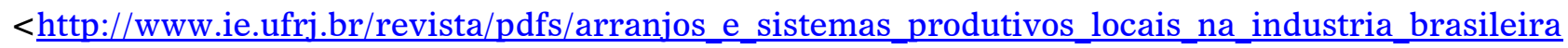
.pdf >. Acesso em: 16 ago. 2012.

CASSIOLATO, J.; SZAPIRO, M. Aglomerações e sistemas produtivos e inovativos locais: em busca de uma caracterização voltada ao caso brasileiro. Rio de Janeiro: IE-UFRJ, 2002.

CAUCHICK MIGUEL, P. A., SOUSA, R. O método do estudo de caso na engenharia de produção. In: Cauchick Miguel P. A. (Ed.). Metodologia de pesquisa em engenharia de produção e gestão de operações. Rio de Janeiro: Elsevier, Abepro, 2012.

CHASE, R. 2015. Peers Inc.: how people and platforms are inventing the collaborative economy and reinventing capitalism. Public Affairs, 2015.

DAROLT, M. R. As principais correntes do movimento orgânico e suas particularidades. In: Darolt M. R. (Ed.). Agricultura orgânica: inventando o futuro. Londrina: IAPAR, 2010.

DE ROLT, C. R.; DIAS, J. S.; PEÑA, F.T. G. Análise de redes como ferramenta de gestão para empreendimentos interorganizacionais. Gestão \& Produção, 24(2), 266-278, 2017.

DEMIRYUREK, K. Analysis of information systems and communication networks for organic and conventional hazelnut producers in the Samsun province of Turkey. Agricultural Systems, 103(7), 444-452, 2010.

GONÇALVES, A. T. P.; LEITE, M. S. A., SILVA, R. M. DA. Um estudo preliminar sobre as definições e as diferenças dos principais tipos de arranjos empresariais. Revista Produção Online, 12(3), 827854, 2012.

KENNEDY, J. Conceptual boundaries of sharing. Information, Communication \& Society, 19(4), 461-474, 2015. Disponível em: < http://dx.doi.org/10.1080/1369118X.2015.1046894 > .

LOUDEN, F. N, MACRAE, R. J. 2010. Federal regulation of local and sustainable food claims in Canada: a case study of Local Food Plus. Agriculture and Human Values, 27(2), 177-188, 2010. Disponível em: < https://doi.org/10.1007/s10460-009-9209-6>.

MAXEY, L. Can we sustain sustainable agriculture? Learning from small-scale producer-suppliers in Canada and the UK. Geographical Journal, 172(3), 230-244, 2006. Disponível em: < http://dx.doi.org/10.1111/j.1475-4959.2006.00211.x> 
MINISTÉRIO DA AGRICULTURA, PECUÁRIA E ABASTECIMENTO - BRASIL. Secretaria de Desenvolvimento Agropecuário e Cooperativismo. Produtos orgânicos: o olho do consumidor. Brasília: MAPA/ACS, 2009.

MINISTÉRIO DA AGRICULTURA, PECUÁRIA E ABASTECIMENTO - BRASIL. Disponível em: <http://www.agricultura.gov.br/assuntos/sustentabilidade/organicos > . Acesso em: 30 abr. 2019a.

MINISTÉRIO DA AGRICULTURA, PECUÁRIA E ABASTECIMENTO - BRASIL. Disponível em: $<$ http://www.agricultura.gov.br/assuntos/sustentabilidade/organicos/cadastro-nacionalprodutores-organicos $>$. Acesso em: 01 maio $2019 \mathrm{~b}$.

PORTER, M. E. Clusters and the new economics competition. Harvard Business Review, 76(6), 77 90, 1998.

PORTAL BRASIL. Disponível em: <http://www.brasil.gov.br/governo/2013/10/dilma-lanca-oplano-nacional-de-agroecologia-e-producao-organica > . Acesso em: 31 mar. 2014.

RAMALHO, F. R. X., SILVA JR, J. T. A emergência do compartilhamento: o futuro da sociedade é colaborativo? NAU Social, 7(12), 2016. Disponível em: < http://www.periodicos.adm.ufba.br/index.php/rs/article/viewArticle/551>.

RETAMALES, J. B. World temperate fruit production: characteristics and challenges. Revista Brasileira de Fruticultura, 33(1), 121-130, 2011. Disponível em: < http://dx.doi.org/10.1590/S0100$\underline{29452011000500015>\text {. }}$

ROTH A. L., WEGNER D., ANTUNES JÚNIOR, J. A. V., PADULA A. D. 2012. Diferenças e interrelações dos conceitos de governança e gestão de redes horizontais de empresas: contribuições para o campo de estudos. Revista de Administração, 47(1), 112-123, 2012. Disponível em: $<$ https://doi.org/10.5700/rausp1029>.

ROVER, O. J. Agroecologia, mercado e inovação social: o caso da Rede Ecovida de Agroecologia. Ciências Sociais Unisinos, 47(1), 56-63, 2011.

STOLZE, M., LAMPKIN, N. Policy for organic farming: rationale and concepts. Food Policy, 34(3), 237-244, $2009 . \quad$ Disponível em: < http://citeseerx.ist.psu.edu/viewdoc/download?doi=10.1.1.460.46\&rep=rep1\&type =pdf $>$.

TRAUGER, A. Un/re-constructing the agrarian dream: going back-to-the-land with an organic marketing co-operative in south-central Pennsylvania, USA. Tijdschrift voor Economische en Sociale Geografiev, 98(1), 9-20, 2007. Disponível em: < http://onlinelibrary.wiley.com/doi/10.1111/j.1467-9663.2007.00372.x/full>.

YIN, R. K. Estudo de caso: planejamento e métodos. Porto Alegre: Bookman, 2010.

ZACCARELLI, S. B.; TELLES R.; SIQUEIRA, JOÃO P. L DE; BOAVENTURA, JOÃO M. G., DONAIRE, D. Clusters e redes de negócios: uma visão para a gestão dos negócios. São Paulo: Atlas, 2008.

ZAHM, F.; VIAUX P.; VILAIN L.; GIRARDIN P. MOUCHET C. Assessing Farm Sustainability with the IDEA Method - from the concept of agriculture sustainability to case studies on farms. Sustainable Development, 16(4), 271-281, 2008. Disponível em: $<\underline{\text { http://onlinelibrary.wiley.com/doi/10.1002/sd.380/full }>\text {. }}$

ZANOLI, R., GAMBELLI, D., VAIRO, D. 2012. Scenarios of the organic food market in Europe. Food Polic, 37(1), 41-57, 2012. Disponível em: <https://doi.org/10.1016/j.foodpol.2011.10.003>. 
ZOLDAN, P.C., MIOR, L.C. Produção orgânica na agricultura familiar de Santa Catarina. Florianópolis: Epagri (Documentos, 239), 2012.

Esta obra está licenciada com uma Licença Creative Commons Atribuição 4.0 Internacional. 